\title{
Detection and Characterization of $\beta$-Lactamase Encoding Genes in Carbapenem Non-Susceptible Gram-Negative Bacteria and Susceptibility of Isolates to Ceftazidime-Avibactam at a New York City Community Hospital
}

\author{
Carl Urban1, Rita Colon-Urban², Vincent J. LaBombardi ${ }^{3}$, Noriel Mariano', Nishant Prasad1, \\ Geeti Dhillon', Marina Guralnik ${ }^{3}$, Sorana Segal-Maurer ${ }^{1}$
}

\author{
${ }^{1}$ The Dr. James J. Rahal, Jr. Division of Infectious Diseases, Department of Medicine, NewYork-Presbyterian/Queens, Flushing, \\ NY, USA \\ ${ }^{2}$ Department of Biological Sciences, SUNY Old Westbury, Old Westbury, New York, NY, USA \\ ${ }^{3}$ Department of Pathology, NewYork-Presbyterian/Queens, Flushing, NY, USA \\ Email: cmurban@nyp.org
}

\begin{abstract}
How to cite this paper: Urban, C., Colon-Urban, R., LaBombardi, V.J., Mariano, N., Prasad, N., Dhillon, G., Guralnik, M. and Segal-Maurer, S. (2016) Detection and Characterization of $\beta$-Lactamase Encoding Genes in Carbapenem Non-Susceptible Gram-Negative Bacteria and Susceptibility of Isolates to Ceftazidime-Avibactam at a New York City Community Hospital. Open Journal of Medical Microbiology, 6, 150157.
\end{abstract}

http://dx.doi.org/10.4236/ojmm.2016.64020

Received: November 5, 2016

Accepted: December 16, 2016

Published: December 19, 2016

Copyright $\odot 2016$ by authors and Scientific Research Publishing Inc.

This work is licensed under the Creative Commons Attribution International

License (CC BY 4.0).

http://creativecommons.org/licenses/by/4.0/

\begin{abstract}
A surveillance study was undertaken to identify prominent $\beta$-lactamase encoding genes in 131 carbapenem non-susceptible gram-negative clinical isolates at a New York City community hospital. KPC carbapenemases were detected in $89 \%$ of Enterobacteriaceae as well as additional TEM, SHV, and CTX-M class A enzymes. OXA23 and OXA-24 were the prevalent class D carbapenemases identified in Acinetobacter species. One OXA-23 in M. morganii and one OXA-48 in $K$. pneumoniae were also identified. Among class C $\beta$-lactamases CMY, ACT/MIR, DHA, and FOX were detected. The in vitro activity of ceftazidime-avibactam by E-test methodology was tested with minimal inhibitory concentrations (MIC) of $\leq 3 \mu \mathrm{g} / \mathrm{ml}$ for $97.8 \%$ of all Enterobacteriaceae, $\mathrm{MIC}_{50 / 90}$ of $16 />256 \mu \mathrm{g} / \mathrm{ml}$ for carbapenem non-susceptible Acinetobacter, and $3 / 6 \mu \mathrm{g} / \mathrm{ml}$ for carbapenem non-susceptible Pseudomonas aeruginosa. Periodic surveillance of isolates to characterize current and emerging $\beta$-lactamase genotypes present in local isolates may help identify outbreak situations, provide assistance to infection control and antibiotic stewardship programs, and potentially improve patient outcomes.
\end{abstract}

\section{Keywords}

Carbapenem Non-Susceptible, Check-MDR CT103 XL Microarray, $\beta$-Lactamase 
Detection, Resistance Mechanisms, Ceftazidime-Avibactam

\section{Introduction}

Carbapenem resistant Enterobacteriaceae (CRE), MDR Pseudomonas aeruginosa (MDRPSA) and MDR Acinetobacter (MDRAC) are urgent and serious threats as designated by the Centers for Disease Control and Prevention (CDC) [1]. Phenotypic expression of carbapenem resistance (reported by many clinical microbiology laboratories) can be due to numerous mechanisms with $\beta$-lactam hydrolyzing enzymes being the major contributor [2]. Therefore, it is important to classify which enzyme(s) is (are) present since detection is a vital component in defining their epidemiology, controlling spread, as well as aiding appropriate early therapeutic interventions. Since our hospital has a long history of $\beta$-lactam resistance present in multi-drug resistant gram-negative bacteria, an investigation was undertaken to characterize current enzymes associated with carbapenem resistant gram-negative bacteria. We also assessed the in vitro activity of ceftazidime-avibactam (CA), which has been shown to inhibit a wide spectrum of $\beta$-lactamase producing organisms, including those with KPC enzymes.

\section{Materials and Methods}

\subsection{Microbiology and Susceptibility}

One-hundred and thirty-one carbapenem non-susceptible gram-negative single-patient clinical isolates from blood, urine, sputum, and stool were identified in our Clinical Microbiology Laboratory using the Vitek $2^{\circledast} \mathrm{GN}$ (gram-negative) ID card (bioMerieux, Durham, NC). Isolates identified from community and hospitalized patients as well as residents of an affiliated long-term care facility (LTCF) were selected from January 2012 through December 2015. Of these, 87 were Enterobacteriaceae consisting of $9 \mathrm{Ci}^{-}$ trobacter species, 29 Escherichia coli, 27 Enterobacter species, 13 Klebsiella pneumoniae, 8 Serratia marcescens and 1 Morganella morganii; 44 were non-fermenters which included 24 carbapenem non-susceptible Pseudomonas aeruginosa and 20 carbapenem non-susceptible Acinetobacter. Susceptibility to CA by E-test methodology was performed according to the manufacturer's specifications (bioMerieux, Durham, NC). Klebsiella pneumoniae ATCC 700603 was tested against CA and ceftazidime alone by E-test methodology to confirm the activity of avibactam.

\subsection{DNA Isolation and Amplification}

Bacteria were grown overnight on TSA II 5\% blood agar plates and DNA was extracted from colonies using the DNeasy ${ }^{\oplus}$ blood and tissue kit (Qiagen Sciences, Germantown, MD). The Check-MDR CT103 XL microarray system was used for detection of $\beta$-lactamases according to manufacturer's instructions (Check points, Wegeningen, Netherlands). A description of the microarray technology and $\beta$-lactamases that can be detected 
has been described in detail [3] [4] [5].

\section{Results}

\section{1. $\beta$-Lactamase Genotypes Identified by Check-MDR CT103 XL Microarray System}

Table 1 lists the enzymes characterized in this study. KPC $\beta$-lactamases were present in 79/87 (91\%) of CRE with 28/29 (97\%) in E. coli, 11/13 (85\%) in K. pneumoniae, 9/9 (100\%) in Citrobacter species (8 Citrobacter freundii, and 1 Citrobacter koserii), 4/8 (50\%) in Serratia marcescens and 19/27 (70\%) in Enterobacter species (4 Enterobacter aerogenes, 21 Enterobacter cloacae, 1 Enterobacter asburiae, and 1 Enterobacter gergoviae). Among E. coli isolates, TEM (18/29, 62\%), SHV (5/29, 17\%), ESBLs (7/29, 24\%), and plasmid-mediated AMP-C (1/29, 3\% ACT/MIR and 1/29, 3\% CMY) enzymes were documented. $K$. pneumoniae isolates harbored TEM (9/13, 69\%), SHV (12/13, 92\%), CTX-M (5/13, 38\%), OXA-48 (1/13, 8\%), and ESBLs (5/13, 38\%) $\beta$-lactamases. In $C i$ trobacter isolates, enzymes detected were TEM (7/9, 78\%), SHV (2/9, 22\%), ESBLs (2/9, $22 \%)$, and plasmid-mediated AMP-C (2/9, 22\% ACT/MIR and 1/9, 11\% CMY). In Enterobacter species, 10/27 (37\%) harbored ESBLs and 20/27 (74\%) possessed plasmid mediated $\beta$-lactamases including ACT/MIR (17/27, 63\%), DHA (2/27, 7\%) and FOX $(1 / 27,4 \%)$. In $S$. marcescens, TEM $(8 / 10,80 \%)$, CTX-M (1/10, 10\%), KPC $(4 / 8,50 \%)$ and ESBLs $(4 / 8,50 \%)$ were characterized. The microarray also characterized OXA-23 in one M. morganii isolate and OXA-48 in one $K$. pneumoniae isolate.

Among non-fermenters, TEM or SHV enzymes (5/20, 25\%), OXA-23 (14/20, 70\%), and OXA-24 (3/20, 15\%) were characterized in Acinetobacter species. TEM (3/24, $13 \%)$, and ESBL $(1 / 24,4 \%)$ were also found in $P$. aeruginosa.

No NDM, VIM, IMP, GIM or SPM metallo- $\beta$-lactamases were identified in any of the isolates.

Table 1. $\beta$-lactamase genotypes identified in 131 carbapenem non-susceptible gram-negative bacteria by Check-MDR CT103 XL microarray system.

\begin{tabular}{|c|c|c|c|c|c|c|c|c|c|c|c|c|}
\hline \multirow{2}{*}{$\begin{array}{c}\text { Bacteria } \\
\text { (no. of isolates) }\end{array}$} & \multicolumn{12}{|c|}{$\beta$-lactamase Genotypes } \\
\hline & TEM & SHV & CTX-M & ESBL & KPC & OXA-23 & OXA-24 & OXA-48 & ACT/MIR & DHA & FOX & $\mathrm{CMY}$ \\
\hline Klebsiella pneumoniae (13) & $9 / 13$ & $12 / 13$ & $5 / 13$ & $5 / 13$ & $11 / 13$ & & & $1 / 13$ & & & & \\
\hline Morganella morganii (1) & & & & & & $1 / 1$ & & & & & & \\
\hline Citrobacter species (9) & $7 / 9$ & $2 / 9$ & & $2 / 9$ & $9 / 9$ & & & & $2 / 9$ & & & $1 / 9$ \\
\hline Acinetobacter species (20) & $2 / 20$ & $3 / 20$ & & $3 / 20$ & & $14 / 20$ & $3 / 20$ & & & & & \\
\hline
\end{tabular}




\subsection{Minimal Inhibitory Concentration of Ceftazidime and Ceftazidime-Avibactam by E-Test Methodology}

Minimal inhibitory concentration (MIC) for CA by E-test (Table 2) was $\leq 2 \mu \mathrm{g} / \mathrm{ml}$ for 88/89 (98.9\%) Enterobacteriaceae tested with one Enterobacter cloacae isolate having an MIC of $3 \mu \mathrm{g} / \mathrm{ml}$. Among carbapenem non-susceptible Pseudomonas aeruginosa, $\mathrm{MIC}_{50 / 90}$ of $12 \mu \mathrm{g} / \mathrm{ml} / 24 \mu \mathrm{g} / \mathrm{ml}$ for ceftazidime, $3 \mu \mathrm{g} / \mathrm{ml} / 6 \mu \mathrm{g} / \mathrm{ml}$ for CA and $>256 />256,16 />256$ $\mu \mathrm{g} / \mathrm{ml}$ for carbapenem non-susceptible Acinetobacter respectively, were recorded.

\section{Discussion}

In this surveillance study designed to identify current $\beta$-lactamases in a New York City hospital, KPC $\beta$-lactamases were the predominant enzymes characterized in carbapenem non-susceptible Enterobacteriaceae and reinforces our previously published studies recognizing such enzymes in hospitalized and community patients and in residents of our associated LTCF [6] [7] [8] [9]. The detection of OXA-48 in K. pneumoniae and OXA-23 in Morganella morganii are novel findings in our isolates. Although OXA-23 has previously been reported in Proteus mirabilis and in E. coli, OXA-23 has never been reported in M. morganii to our knowledge [10] [11]. Among class C enzymes, the detection of DHA and FOX in Enterobacter species and CMY in E. coli and Citrobacter species were also new findings in our isolates. CMY-II, ACT-1, FOX, and DHA plasmid mediated amp $C$ enzymes in conjunction with loss of outer membrane porins, can lead to treatment failure with carbapenem monotherapy [12] [13] [14] [15]. Recognition of these enzymes with genotypic methods may also support more timely infection control intervention as we and others have previously demonstrated in the setting of carbapenem resistant $K$. pneumoniae outbreaks [14] [15]. The detection of OXA-23 in $M$. morganii was a serendipitous finding and would not have been recognized with earlier

Table 2. Minimal inhibitory concentration of ceftazidime and ceftazidime-avibactam by E-test methodology.

\begin{tabular}{|c|c|c|c|c|c|}
\hline Bacteria (no. of isolates) & $\begin{array}{c}\text { Ceftazidime } \\
\operatorname{MIC}_{50 / 90}(\mu \mathrm{g} / \mathrm{ml})\end{array}$ & Range & $\begin{array}{l}\text { Ceftazidime avibactam } \\
\operatorname{MIC}_{50 / 90}(\mu \mathrm{g} / \mathrm{ml})\end{array}$ & Range & $\begin{array}{c}\text { Ceftazidime avibactam breakpoints } \\
\text { susceptible/resistant }(\mu \mathrm{g} / \mathrm{ml})\end{array}$ \\
\hline Escherichia coli (29) & $96.0 />256$ & $8.0->256$ & $0.5 / 1$ & $0.016-2$ & $\leq 8 / 4 / \geq 16 / 4$ \\
\hline Klebsiella pneumoniae (13) & $64.0 />256$ & $12.0->256$ & $1.0 / 2$ & $0.25-2$ & $\leq 8 / 4 / \geq 16 / 4$ \\
\hline Enterobacter species (27) & $32.0 / 256$ & $0.38->256$ & $0.5 / 1.5$ & $0.19-3$ & $\leq 8 / 4 / \geq 16 / 4$ \\
\hline Morganella morganii (1) & N/A & 3 & N/A & 3 & $\leq 8 / 4 / \geq 16 / 4$ \\
\hline Citrobacter species (9) & N/A & $1->256$ & N/A & $0.94-1.5$ & $\leq 8 / 4 / \geq 16 / 4$ \\
\hline Acinetobacter species (20) & $>256 />256$ & $0.75 .0->256$ & $24.0->256$ & $0.75->256$ & N/A \\
\hline Serratia marcescens $(8)$ & N/A & $1.0->256$ & N/A & $0.064-192$ & $\leq 8 / 4 / \geq 16 / 4$ \\
\hline Pseudomonas aeruginosa (24) & $12 / 24$ & $1.5->256$ & $3.0 / 6$ & $0.75-8$ & $\leq 8 / 4 / \geq 16 / 4$ \\
\hline $\begin{array}{l}\text { Klebsiella pneumoniae } \\
\text { ATCC } 700603 \text { control }\end{array}$ & 24 & N/A & 1 & N/A & $\leq 2 />16$ \\
\hline
\end{tabular}

$\mathrm{N} / \mathrm{A}=$ not applicable. 
Check MDR microarray systems or other commercially available systems. These enzymes are not inhibited by any current $\beta$-lactamase inhibitors, including avibactam. This is delineated in Table 2 with no difference in MICs $(3 \mu \mathrm{g} / \mathrm{ml})$ between ceftazidime alone and CA. This is in contrast to the OXA-48 enzyme found in $K$. pneumoniae which is inhibited by avibactam, (MIC for ceftazidime $=128 \mu \mathrm{g} / \mathrm{ml}$, MIC for CA $=0.75$ $\mu \mathrm{g} / \mathrm{ml})$. Among Acinetobacter isolates, OXA-23 and OXA-24 were the predominant carbapenemases, a finding consistent with our earlier studies [16] [17]. While all $P$. aeruginosa in this study were reported as carbapenem resistant by the Vitek $2^{\circledR}$ system, the Check-MDR CT103 XL Microarray reported no carbapenem resistant genotypes likely due to lack of specific ampC primers for Pseudomonas aeruginosa. To our knowledge, no commercial system is available to detect such enzymes.

Carbapenem resistance in Pseudomonas aeruginosa can be due to the interplay of up regulated efflux, chromosomal ampC $\beta$-lactamase production, and diminished oprD [18]. Thus, both phenotypic and genotypic testing may be necessary for better prediction of antibacterial resistance and opportunity for better directed therapy in these and additional isolates expressing these determinants.

An earlier study evaluating the in vitro activity of CA against all Enterobacteriaceae isolates from US hospitals with characterization of associated $\beta$-lactamases, documented $\mathrm{MIC}_{50 / 90}$ of $0.12 / 0.25 \mu \mathrm{g} / \mathrm{ml}$ for CA [19]. In contrast, we found $\mathrm{MIC}_{50 / 90}$ of $0.5 /$ $1.5 \mu \mathrm{g} / \mathrm{ml}$ for carbapenem non-susceptible strains. Another survey, which also characterized such isolates and their susceptibility to $\mathrm{CA}$, reported $\mathrm{MIC}_{50 / 90}$, of $1 / 1 \mu \mathrm{g} / \mathrm{ml}$ [20]. Although not assessed in our study, elevated MICs have been associated with KPC-3 strains of $K$. pneumoniae as well as strains with ESBLs and porin mutations and this is an area for future investigation [21].

We have previously used other molecular techniques to characterize $\beta$-lactamase encoding genes in $24 \%$ of the isolates analyzed in this study [7] [8] [22] [23] LaBombardi VJ, unpublished results]. However, recent studies have demonstrated sensitivities and specificities of $100 \%$ and accuracies of $94 \%$ for the detection of known resistance genes using the Check-Points MDR CT103 XL microarray kit $(4,5)$.

In conclusion, we have identified class $\mathrm{A}, \mathrm{C}$ and $\mathrm{D} \beta$-lactamase encoding genes in carbapenem non-susceptible gram-negative clinical isolates at our community hospital in New York City. Molecular characterization in conjunction with phenotypic reporting by clinical microbiology laboratories can provide a "snapshot" of enzymes present within a geographical area, can support antibiogram data and reveal $\beta$-lactamases that are "silently disseminating" [24] [25]. Genotypic results from systems such as the one used in this study may answer the question: "are susceptibility tests enough, or should laboratories still seek ESBLs and carbapenemases directly?" [26]. Periodic sampling such as this may be beneficial to describe epidemiologic evolution of carbapenem resistant organisms. Combining phenotypic and genotypic data has significant potential for identifying unrecognized reservoirs in both hospital and LTCFs, can be instrumental in detecting outbreaks, and provide assistance to infection control and antibiotic stewardship programs which can potentially improve patient outcomes. 


\section{References}

[1] Centers for Disease Control and Prevention (CDC) (2013) Antibiotic Resistance Threats in the United States. CDC, Atlanta.

[2] Bush, K. (2013) The ABCD's of $\beta$-Lactamase Nomenclature. Journal of Infection and Chemotherapy, 19, 549-559. https://doi.org/10.1007/s10156-013-0640-7

[3] Check-MDR CT103 XL User Manual, Version 1.0, 1-08-2014 Check Points, Wegeningen, Netherlands.

[4] Bogaerts, P., Cuzon, G., Evrard, S., Hoebeke, M., Naas, T. and Glupczynski, Y. (2016) Evaluation of a DNA Micro Array for Rapid Detection of the Most Prevalent Extended-Spectrum $\beta$-Lactamases, Plasmid-Mediated Cephalosporinases and Carbapenemases in Enterobacteriaceae, Pseudomonas and Acinetobacter. International Journal of Antimicrobial Agents, 48, 189-193. https://doi.org/10.1016/j.ijantimicag.2016.05.006

[5] Cunningham, S.A., Vasoo, S. and Patel, R. (2016) Evaluation of the Check-Points Check MDR CT103 and CT103 XL Microarray Kits by Use of Preparatory Rapid Cell Lysis. Journal of Clinical Microbiology, 54, 1368-1371. https://doi.org/10.1128/JCM.03302-15

[6] Urban, C., Bradford, P.A., Tuckman, M., Segal-Maurer, S., Wehbeh, W., Grenner, L., Colon-Urban, R., Mariano, N. and Rahal, J.J. (2008) Carbapenem-Resistant Escherichia coli Harboring Klebsiella pneumoniae Carbapenemase $\beta$-Lactamases Associated with LongTerm Care Facilities. Clinical Infectious Diseases, 46, e127-e130.

https://doi.org/10.1086/588048

[7] Tiruvury, H., Johnson, J.R., Mariano, N., Grenner, L., Colon-Urban, R., Erritouni, M., Wehbeh, W., Segal-Maurer, S., Rahal, J.J., Johnston, B. and Urban, C. (2012) Identification of CTX-M $\beta$-Lactamases among Escherichia coli from the Community in New York City. DiagMicrobiol Infect Dis, 72, 248-252. https://doi.org/10.1016/j.diagmicrobio.2011.11.008

[8] Kopacz, J., Mariano, N., Colon-Urban, R., Sychangco, P., Wehbeh, W., Segal-Maurer, S., and Urban C (2013) Identification of Extended-Spectrum- $\beta$-Lactamase-Positive Klebsiella pneumoniae Urinary Tract Isolates Harboring KPC and CTX-M $\beta$-Lactamases in Nonhospitalized Patients. Antimicrob Agents Chemother, 57, 5166-5169.

https://doi.org/10.1128/AAC.00043-13

[9] Urban, C., Mariano, N., Bradford, P.A., Tuckman, M., Segal-Maurer, S., Wehbeh, W., Grenner, L., Colon-Urban, R., Johnston, B., Johnson, J.R. and Rahal, J.J. (2010) Identification of CTX-M $\beta$-Lactamases in Escherichia coli from Hospitalized Patients and Residents of Long-Term Care Facilities. Diagnostic Microbiology and Infectious Disease, 66, 402-406. https://doi.org/10.1016/j.diagmicrobio.2009.11.012

[10] Österblad, M., Karah, N., Halkilahti, J., Sarkkinen, H., Uhlin, B.E. and Jalava, J. (2016) Rare Detection of the Acinetobacter Class D carbapenemase blaOXA-23 Gene in Proteus Mirabilis. Antimicrobial Agents and Chemotherapy, 60, 3243-3245.

https://doi.org/10.1128/AAC.03119-15

[11] La, M-V., Jureen, R., Lin, R.T.P. and Teo, J.W.P. (2014) Unusual Detection of an Acinetobacter Class D Carbapenemase Gene blaoxa-23, in a Clinical Escherichia coli Isolate. Journal of Clinical Microbiology, 52, 3822-3823. https://doi.org/10.1128/JCM.01566-14

[12] Mammeri, H., Guillon, H., Eb, F. and Nordmann, P. (2010) Phenotypic and Biochemical Comparison of the Cabapenem-Hydrolyzing Activities of Five Plasmid-Borne AmpC $\beta$-lactamases. Antimicrobial Agents and Chemotherapy, 54, 4556-4560. http://dx.doi.org/10.1128/AAC.01762-09

[13] Bradford, P.A, Urban, C., Mariano, N., Projan, S.J., Rahal, J.J. and Bush, K. (1997) Imipenem Resistance of Clinical Isolates of Klebsiella pneumoniae Results from ACT-1, a Plas- 
mid Mediated AMP C Beta-Lactamase Combined with Loss of Membrane Porin Proteins. Antimicrobial Agents and Chemotherapy, 41, 563-569.

[14] Ahmad, M., Urban, C., Mariano, N., Bradford, P., Calcagni, E., Projan, S., Bush, K. and Rahal, J.J. (1999) Clinical and Molecular Epidemiology Associated with Imipenem Resistant Klebsiella pneumoniae. Clinical Infectious Diseases, 29, 352-355. https://doi.org/10.1086/520214

[15] Matsumura, Y., Tanaka, M., Yamamoto, M., Nagao, M., Machida, K., Ito, Y., Takakura, S., Ogawa, K., Yoshizawa, A., Fujimoto, Y., Oamoto, S., Uemoto, S. and Ichiyama, S. (2015) High Prevalence of Carbapenem Resistance among Plasmid-Mediated AmpC $\beta$-LactamaseProducing Klebsiella pneumoniae during Outbreaks in Liver Transplantation Units. International Journal of Antimicrobial Agents, 45, 33-40. https://doi.org/10.1016/j.ijantimicag.2014.08.015

[16] Abdallaha, M., Olafisoyea, O., Cortes, C., Urban, C., Landman, D. and Quale, J. (2015) Activity of Eravacycline against Enterobacteriaceae and Acinetobacter baumannii, Including 2 Multidrug-Resistant Isolates, from New York City. Antimicrobial Agents and Chemotherapy, 59, 1802-1805. https://doi.org/10.1128/AAC.04809-14

[17] Adams-Haduch, J.M., Onuoha, E.O., Bogdanovich, T., Tian, G.B., Marschall, J., Urban, C.M., Spellberg, B.J., Rhee, D., Halstead, D.C., Pasculle, A.W. and Doi, Y. (2011) Molecular Epidemiology of Carbapenem-Nonsusceptible Acinetobacter baumannii in the United States. Journal of Clinical Microbiology, 49, 3849-3854. https://doi.org/10.1128/jcm.00619-11

[18] Quale, J., Bratu, S., Gupta, J., and Landman, D. (2006) Interplay of Efflux System, ampC, and oprD Expression in Carbapenem Resistance of Pseudomonas aeruginosa Clinical Isolates. Antimicrobial Agents and Chemotherapy, 50, 1633-1641. https://doi.org/10.1128/AAC.50.5.1633-1641.2006

[19] Castanheira, M., Mills, J.C., Costello, S.E., Jones, R.N., and Sader, H.S. (2015) Ceftazidime-Avibactam Activity Tested against Enterobacteriaceae Isolates from U.S. Hospitals (2011-2013) and Characterization of $\beta$-Lactamase-Producing Strains. Antimicrobial Agents and Chemotherapy, 59, 3509-3517. https://doi.org/10.1128/AAC.00163-15

[20] Dupont, H., Gaillot, O., Goetgheluck, A.S., Plassart, C., Emond, J.P., Lecuru, M., Gaillard, N., Derdouri, S., Lemaire, B., Girard de Courtilles, M., Cattoir, V. and Mammeri, H. Molecular Characterization of Carbapenem-Nonsusceptible Enterobacterial Isolates Collected during a Prospective Interregional Survey in France and Susceptibility to the Novel Ceftazidime-Avibactam and Aztreonam-Avibactam Combinations. Antimicrobial Agents and Chemotherapy, 60, 215-221. https://doi.org/10.1128/AAC.01559-15

[21] Shields, R.K., Clancy, C.J., Hao, B., Chen, L., Press, E.G., Iovine, N.M., Kreiswirth, B.N. and Nguyen, M.H. (2015) Effects of Klebsiella pneumoniae Carbapenemase Subtypes, Extended Spectrum $\beta$-Lactamases, and Porin Mutations on the in Vitro Activity of CeftazidimeAvibactam against Carbapenem-Resistant K. pneumoniae. Antimicrobial Agents and Chemotherapy, 59, 5793-5797. https://doi.org/10.1128/AAC.00548-15

[22] LaBombardi, V.J., Urban, C.M., Kreiswirth, B.N., Chen, L., Osorio, G., Kopacz, J., Labaze, G. and Segal-Maurer, S. (2015) Evaluation of Remel Spectra CRE Agar for Detection of Carbapenem-Resistant Bacteria from Rectal Swabs Obtained from Residents of a LongTerm-Care Facility. Journal of Clinical Microbiology, 53, 2823-2826.

https://doi.org/10.1128/JCM.00789-15

[23] Prasad, N., Labaze, G., Kopacz, J., Chwa, S., Platis, D., Pan, C.X., Russo, D., LaBombardi, V.J., Osorio, G., Pollack, S., Kreiswirth, B.N., Chen, L., Urban, C. and Segal-Maurer, S. (2016) Asymptomatic Rectal Colonization with Carbapenem-Resistant Enterobacteriaceae 
and Clostridium difficile among Residents of a Long-Term-Care Facility in New York City. American Journal of Infection Control, 44, 525-532.

https://doi.org/10.1016/j.ajic.2015.11.021

[24] Viau, R.A., Hujer, A.M., Marshall, S.H., Perez, F., Hujer, K.M., Brice-o, D.F., Dul, M., Jacobs, M.R., Grossberg, R., Toltzis, P. and Bonomo, R.A. (2012) "Silent" Dissemination of Klebsiella pneumoniae Isolates Bearing $K$. pneumoniae Carbapenemase in a Long-Term Care Facility for Children and Young Adults in Northeast Ohio. Clinical Infectious Diseases, 54, 1314-1321. https://doi.org/10.1093/cid/cis036

[25] Sahin, K., Tekin, A., Ozdas, S., Akin, D., Yapislar, H., Dilek, A.R. and Sonmez, E. (2015) Evaluation of Carbapenem Resistance Using Phenotypic and Genotypic Techniques in Enterobacteriaceae. Annals of Clinical Microbiology and Antimicrobials, 14, 44. https://doi.org/10.1186/s12941-015-0105-1

[26] Livermore, D.M., Andrews, J.M., Hawkey, P.M., Ho, P.L., Keness, Y., Doi, Y., Paterson, D. and Woodford, N. (2012) Are Susceptibility Tests Enough, or Should Laboratories Still See ESBLs and Carbapenemases Directly? Journal of Antimicrobial Chemotherapy, 67, 15691577. https://doi.org/10.1093/jac/dks088

\section{Submit or recommend next manuscript to SCIRP and we will provide best service} for you:

Accepting pre-submission inquiries through Email, Facebook, LinkedIn, Twitter, etc.

A wide selection of journals (inclusive of 9 subjects, more than 200 journals)

Providing 24-hour high-quality service

User-friendly online submission system

Fair and swift peer-review system

Efficient typesetting and proofreading procedure

Display of the result of downloads and visits, as well as the number of cited articles

Maximum dissemination of your research work

Submit your manuscript at: http://papersubmission.scirp.org/

Or contact ojmm@scirp.org 